\title{
Method of Reduction of Geodynamical Phenomena Catastrophical Effects on the Base of Multichannel Methods of the Precursors Finding
}

\author{
Vladimir Makarov* \\ Department of Mining and Integrated Development of Geo-resources, School of Engineering, Far \\ Eastern Federal University, Vladivostok, Russia.
}

\begin{abstract}
Decrease in risk of catastrophic consequences of the geodynamic phenomena of phylum of rock bursts or earthquakes demands the development of prognosis base of these events. Research of laws of formation and development of mesocracking structures on rocks samples is the most effective path of dilating of representations about mechanisms of the geodynamic phenomena and working out of methods of reduction of risks of their catastrophic exhibitings. Mathematical modelling of mesocracking structures of various hierarchical level of geomedium demands, in turn, development of theoretical base of modelling, to transferring to calibrating models of mesomechanics. In this case, of the geomedium is represented as a thermodynamically open hierarchical-block system. Addition of such models with system of strength criteria reflecting mechanisms of shear-tension of destruction at strong compression, should become the forecasting base of preparation of the geodynamic phenomena. The methods of detection of the precursors including as precursors developed on the basis of these representations, falling into source, and to near the source areas, have multichannel character. It is defined by conditions, on the one hand, independence of such systems of precursors, and, with another one - a simultaneity and synchrony of the submitted signals serving by precursors.
\end{abstract}

\section{Introduction}

The risk of catastrophic consequences of geodynamic processes has sharply increased last decades to scales of a problem of global geoecological crises. It is caused by growth of the population and technological development of a civilisation. It conducts to development of representations about mechanisms of formation of the macrodestruction source and the precursors bound to them, demands development of representations about mesocracking structure of the source area of macrodestruction preparation [1]. Positioned in near the source areas of preparation of earthquakes of a region of acoustic calm, abnormal effects of "reversive" deforming of rock samples at compression [2, 3] allow to speak about

\footnotetext{
*Corresponding author: vlmvv@mail.ru
} 
formation in a prefailure state of rock mesocracking structures of "contrast" phylum at various hierarchical levels of block geomedium. Working out of non-Euclidian gauge models of the rock sample and a massif, is based on a principle of « non-Euclidian hierarchy» and educes by the Far East school of geomechanics [4].

The geological medium has hierarchically block character that essentially complicates an determination of laws of its destruction and forces to evolve objects of research depending on the taken over scale level of modularity [5]. In conformity with the taken over classification by exhibiting scales the geodynamic phenomena are divided into earthquakes (earth crust scale) and rock bursts (scale of mineral deposits fields) table 1. [6].

Table 1. Classification of the geodynamic phenomena [6].

\begin{tabular}{|c|c|c|c|c|c|}
\hline \multicolumn{7}{|c|}{ Classes of the geodynamic phenomena } \\
\hline $\begin{array}{c}\text { Rock } \\
\text { bursts }\end{array}$ & $\begin{array}{c}\text { Gas } \\
\text { blowouts }\end{array}$ & $\begin{array}{c}\text { Exhausts of } \\
\text { coal (rock) } \\
\text { and gas }\end{array}$ & $\begin{array}{c}\text { Mining tectonic } \\
\text { phenomena }\end{array}$ & $\begin{array}{c}\text { Tectonic } \\
\text { phenomena }\end{array}$ & $\begin{array}{c}\text { Outbreak } \\
\text { of water } \\
\text { (clay) }\end{array}$ \\
\hline
\end{tabular}

By United Nations definition concern scratches of catastrophic consequences of earthquakes expected losses during the forecast [7, 8]. According to the newest researches made by one of the most authoritative explorers by professor Hudson and President ISRM in 2012 - 2016 professor Feng [1], the factors defining degree a scratch, correspond to classification presented on drawing 1. One of major factors is level of understanding of mechanisms of the geodynamic phenomena and the analytical calculations corresponding to them made prior to the beginning of realization of engineering decisions.

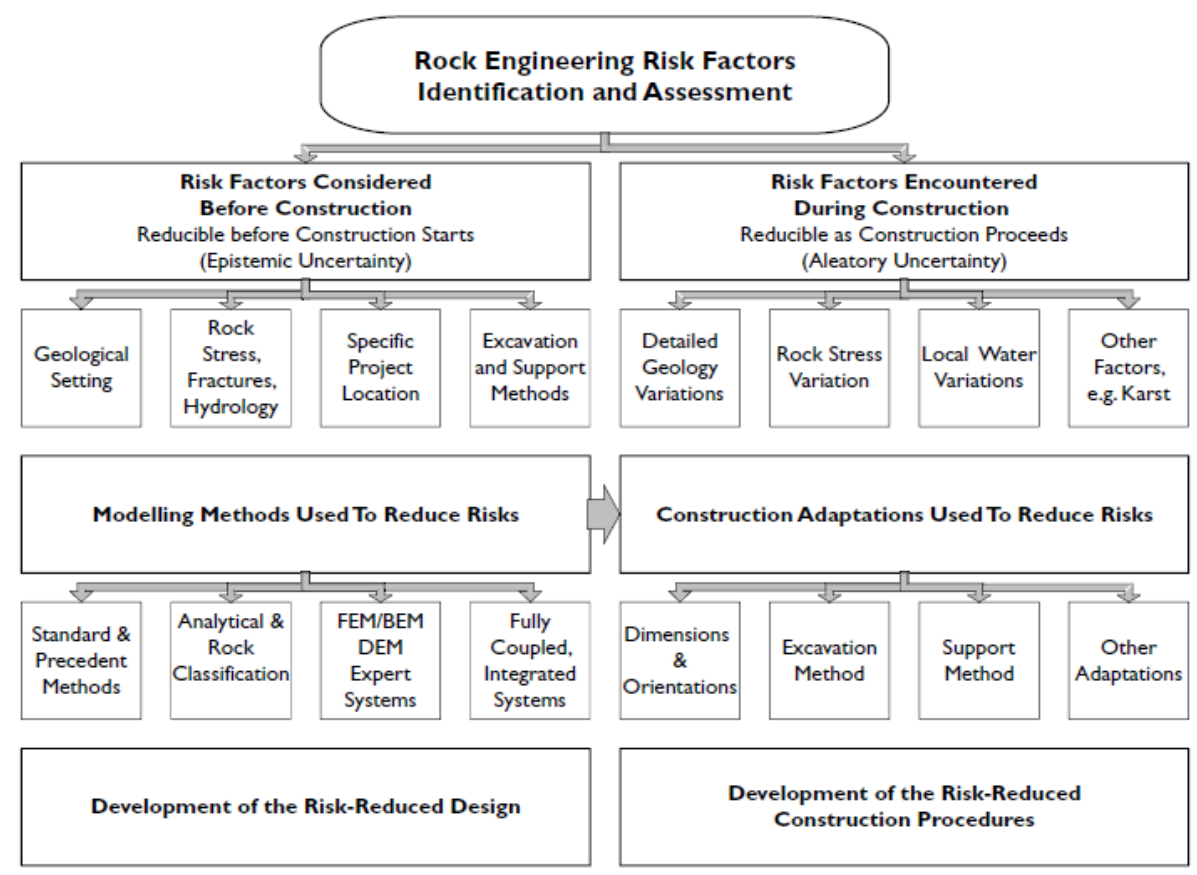

Fig. 1. Classification of risk factors of catastrophic consequences of earthquakes [1]. 
In proceedings of the winner of the award of Leopold Müller (ISRM) professor H.Einstein [9] the concept of the Risk analysis is developed, meaning application of settlement procedures of critical states of engineering designs, including earthquakes subject to seismic influences educes. Taken over in the USA in 1977 the National program of decrease in catastrophic consequences of the connatural phenomena (National Earthquake Hazards Reduction Program (NEHRP)) evolves two basic directions of risks at earthquakes - probability of settlement a terrestrial surface and their frequency [10]. Thus the basic attention has been given research of the causes of occurrence of earthquakes and possibilities of an exact prediction of the moment of their occurrence [11].

These two directions became further the cores by working out of questions of decrease in risks of catastrophic consequences of the geodynamic phenomena. And communication of the specified directions with each other became more and more obvious with development and an excavation of researches. In paper [12] it is noticed that despite huge attention to researches of mechanisms of the earthquakes, existing level of knowledge does not allow to carry out the forecast with demanded accuracy.

Authors explain the conclusions by the complexity of processes of destruction, nonlinear character of their preparation that conducts to basic impossibility of the reliable forecast. Thus, the pessimistic view on possibility of the reliable forecast becomes again the core in modern geomechanics.

Questions of working out of reliable methods of definition of precursors of the geodynamic phenomena have penetrating history on which extent of representation about basic possibility of the forecast were replaced by the seasons of optimism and full pessimism $[13,14,15]$. The initial stage of researches was accompanied by allocation of the basic precursors, the formulation of possibility of a prediction of geodynamic events for decrease in risk of their negative consequences [16, 17]. As precursors abnormal weather conditions, behaviour of animals, electrical effects, a luminescence were offered at earthquake, terrestrial inflows, changes in temperature of hot wells and micro earthquakes. Such phenomena as fluctuations of the earth and terrestrial pulsings, change of terrestrial magnetism, change of temperature of rocks, long-term change in topography etc., but satisfactory results have not been received $[18,19]$.

In G.F.Rejda's proceedings, apparently for the first time it was offered to use deformation precursors of macrodestruction at appearance of faults [20]. Representations about necessity of carrying out of special researches for increase of efficacy of the forecast were gradually formed [21-23]. However, numerous failures at attempt of the forecast of earthquakes have led to formation of representations about impossibility of an exact prediction.

In the forties of 20 centuries these fears only strengthened, as 40 years of researches have not yielded encouraging results. In 1910-1960 in a number of publications it was offered to use as precursors the deformation anomalies previous earthquake, a luminescence before earthquake, geodetic precursors, and also abnormal behaviour of animals.

In the late sixties and in 70th years of 20 centuries the theoretical base of the forecast of the geodynamic phenomena, first in the USSR, the USA and Japan intensively educes [24]. It concerns both forecast methods, and new models of a seismic source. The number of successful predictions increases, the new criteria bound to physics of a seismic source, such as dilatancy, the attitude of speeds of seismic waves and others are introduced. There is a hope of success in the forecast [25].

However, the new level of development of the theory of the forecast of the geodynamic phenomena has not led to essential results in increase of reliability of a prediction of approach of seismic event [26, 27]. As it is underlined in paper [27], all offered models of 
the source have the qualitative character; separate attempts of quantitative calculations have not led to serious generalisations.

The cause consists, first of all, that at enthusiasm for theoretical and experimental researchs with a stuff of rocks from a field of vision of explorers the geomedium, process of its development as a result of earth crust evolution has disappeared. And though last decades development of the theory of the forecast has been continued, requirements to the precursors have been formulated, consisting that they should be authentically measured and unequivocally identified, however that pessimistic point of view which expressed in the XX-th century beginning, again has prevailed [28]. Therefore has ripened necessity of change of a paradigm of the forecast which consists that the geomedium is self-similar hierarchically block system where in the course of evolution in source areas there are mesostructurses of "contrast" phylum (fig. 2) [28].

Appearance of two information channels of precursors (activization and calm) instead of one (activization) capably sharply to increase reliability of the forecast. However, mechanisms of formation of mesostructures are insufficiently clear. It demands carrying out of special researches, working out of a mathematical model of formation and mesostructure development, and also definition of system of the new precursors including long-term and intermediate term.
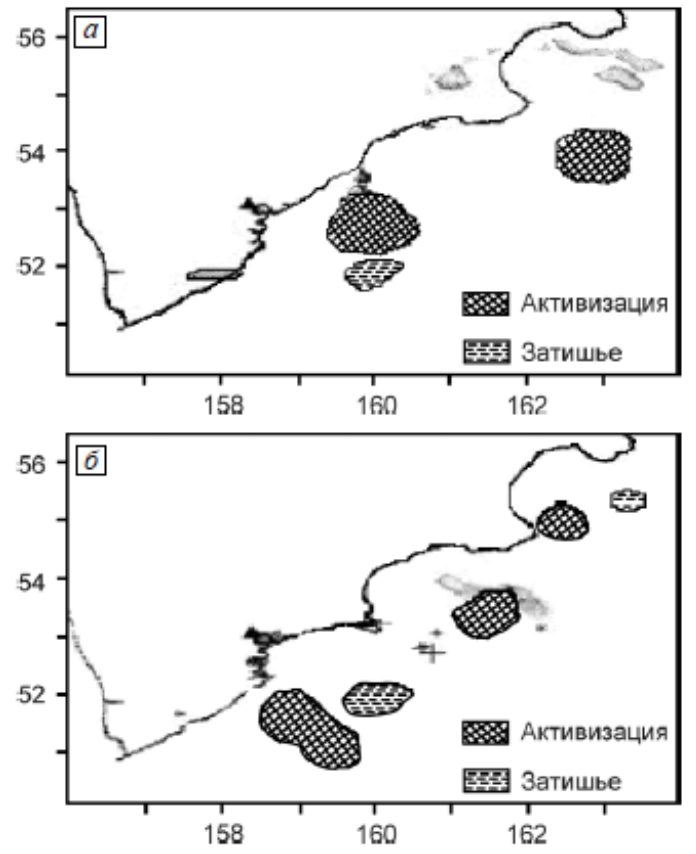

Fig. 2. Anomaly of activation and calm of the Kamchatka earthquake: 1992; 1993 [28].

\section{Experimental research of regularity of a straining of rocks samples in the source of macrofailure and its neighbourhoods}

Based on previous researches, a two-phase model of the macrocracks formation, consisting of a period of scattered microcracking followed by a stage of formation of the source of macrofailure and then macrodefect development, has been assumed [29]. The source is often modelled by inhomogeneity in the form of the soft inclusion, causing the formation 
round it an area of consolidation as the result of redistribution of stress [30, 31]. Modern methods of research applying servocontrolled rigid loading devices allow measurements to be taken directly before, and multichannel measurement systems- to research the behavior of the sample as a whole, including around the site of the failure source.

The technique of multipoint deformation research of strongly compressed samples of rocks provides uniaxial loading of samples by the servocontrolled rigid loading machine MTS-816. This uses resistance strain gauges as a way of taking local measurement of deformations, both in the central part of the sample, and on its height. Thus the «cross» form of the resistance strain gauge allows measurements to be taken of both the longitudinal and lateral strains in a single position, which eliminates the possibility of the joining of individual measurements of the different processes. The conditions of loading, end face conditions and sizes of the samples at compression are accepted, taking into account the effect of contacts of end faces with a load machine [32].

Researches was accomplished on samples of various rocks, including dacites, rhyolite, diorite, granite-porphyry and others. Resistance strain gauges were attached at equal intervals on the whole of the sample, with from four to eight pairs in each row and from one (in the middle) to three rows in height. The special scheme of their fastening has been developed to preserve the wire ends on the sample. The reading from the resistance strain gauges were fixed by means of a computer program on the multichannel device UIU-2002. This researches was carried out at the Geomechanics Laboratories at FEFU.

In Figure 1b, the schema of the sensors displacement is shown during tests. In total, 4 series on 10 samples were tested. The tests were carried out at uniaxial compression of samples under the multipoint schema of measurements from 8 to 48 sensors and $6 \mathrm{AE}$ gauges (Figure 3).

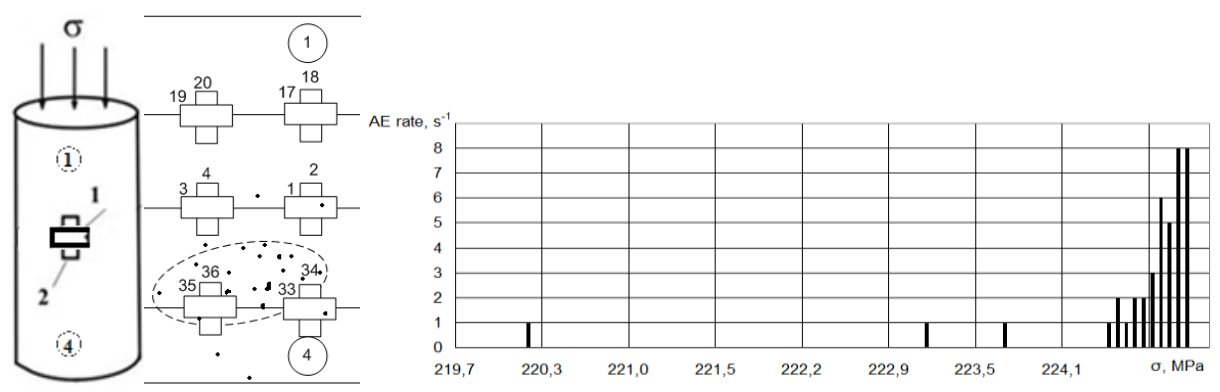

Fig. 3. Schema of measurements ( $a, b)$ of a sample of dacite, source position (ellipse on b) and change of $\mathrm{AE}$ intensity (c): $1,2 \ldots-$ numbers of deformation sensors; 1 and 4 in circulars - AE gauges.

The source position was fixed according to acoustic tests using a device "InterUnis". The change of AE intensity during the time of loading is shown in Figure 1c. It can be seen from Figure 1c, that the cracking process begins at a level of loading of $224 \mathrm{MPa}$, which corresponds to the moment of the deflection of the stress strain curves from a linear relation. The position of the source of failure concerning to pairs of deformation gages is shown in Figure 1a, b. The basic results of the tests of the deformation laws of rock samples in a prefailure state can be reduced to the following. In a prefailure stage of loading a series of anomalous deformation effects which could be used as precursors is observed.

First, this flattening out of the deformation curves with reduction by it fields of modules of deformations in 1.5-3 and more times can be seen in Figure 4a. It is displayed especially clearly in the source area, as shown in Figure $4 \mathrm{~b}$. In this part, 
there are two anomalous deformation effects where, apart from the already noted effect of significant (repeated) decreases of the module of deformation, there are naturally fixed sharp augmentations of the increments of lateral deformations, which are comparable in size or even exceeding the increments of longitudinal strain. The first anomalous effect can be considered to be within the frame of the model of "soft inclusion», as already mentioned above.
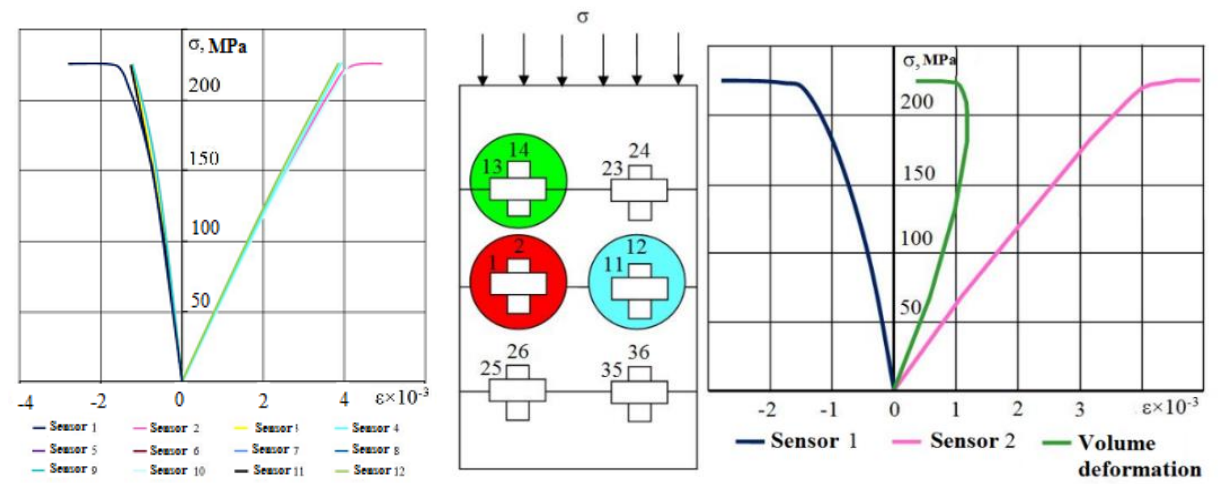

Fig. 4. Laws of deforming of rock samples: a. - prefailure stage of loading: linear strains, the central area of sample; $b$ - character of linear strains in source part of the sample (red color).

\section{Source model of "soft inclusion" with reference to samples of rocks at axial compression}

Modelling source areas by «soft inclusion» is good knowing in Geomechanics [33]. The inclusion can be ideal soft at the rock module of deformation $\mathrm{E}=0$. It is a case of circular hole in a semiplane with evenly distributed of symmetrical load on a part of its border. The problem such is considered by the author in [31], where the character of the displacements of a contour of the hole is shown as in Table 1 and Figure 5.

The second deformation anomaly of the source area, consisting of large lateral strains, as a rule, exceeding the longitudinal increments of deformations, can be explained by a sheartension character of a meso-defect part of the source developmental, leading to the wedge action of such defects [34]. Within the frame of the "soft inclusion" model, this effect cannot be considered directly, as the Poisson's ratio of a continuous material cannot exceed 0.5 .

Properties of the source area of the sample are formed by the cause of defects of the shear-tension type, where the wedge action of a shift element prevails [34]. Therefore, research on mechanisms of deformation anomalies should be divided into two stages, caused by the presence of two source deformation anomalies: longitudinal and across the direction of loading.

Direct overseeing by deformations of areas of rocks testify the same character is lower and nearer to the source (Figure $6 \mathrm{~b}, 7 \mathrm{~b}$ respectively) also. On border of the source area and the surrounding material, the condition of a continuity of displacements is met, so it is logical to expect deformation anomalies not only in the source area, but also in the adjoining parts of the rock. 


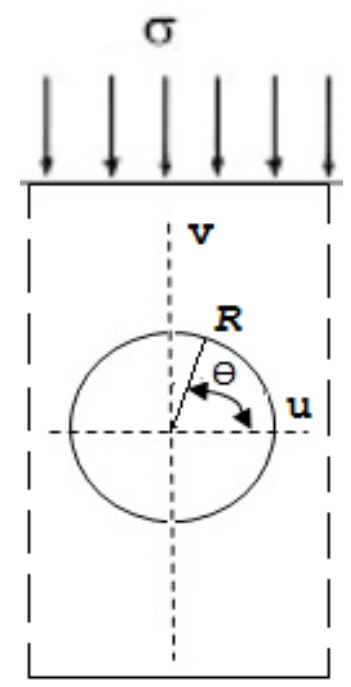

Fig. 5. Design scheme.

Table 2. Classification of the geodynamic phenomena [6].

\begin{tabular}{|c|c|c|}
\hline \multirow{2}{*}{$\boldsymbol{\theta}$, (degree) } & \multicolumn{2}{|c|}{ Displacements } \\
\cline { 2 - 3 } & $\mathrm{u} / \mathrm{R}$ & $\mathrm{v} / \mathrm{R}$ \\
\hline 90 & 0 & $-1,321$ \\
\hline 60 & $-0,011$ & $-0,827$ \\
\hline 30 & 0,610 & $-0,142$ \\
\hline 0 & 1,029 & $-0,071$ \\
\hline-30 & 0,567 & 0,018 \\
\hline-60 & $-0,012$ & 0,664 \\
\hline-90 & 0 & 1,104 \\
\hline
\end{tabular}

The procedure considered above allows making such researches, the results of which are shown in Figure 4, 5. The gauges located immediately under the source part of the sample have fixed the negative increments of the deformations, similar to the results described in [35]. At rising of strains, there is an original revers of linear strains and this can be called a phenomenon of reversible linear deforming in the immediate vicinity of source areas of the rock sample at uniaxial compression. The size of negative increments of longitudinal strain in this case exceeds the size of the negative increments of lateral deformations (Figure 6b). The reversible deforming of that part of the sample which also adjoins the source area has a different character from the part of the sample in a direction perpendicular to the course of the load action (Figure 7b). In this case, by contrast, the size of the negative increments of lateral deformations exceeds the size of the negative increments of longitudinal strain. Sometimes only negative increments of lateral deformations are identified.

Thus, the results of complex acoustic, deformation and theoretical tests allow us to formulate a hypothesis of the conditionality of reversible linear strains of rocks samples in immediate proximity of source area by specificity of defective heterogeneity deforming which can be presented the source area. 


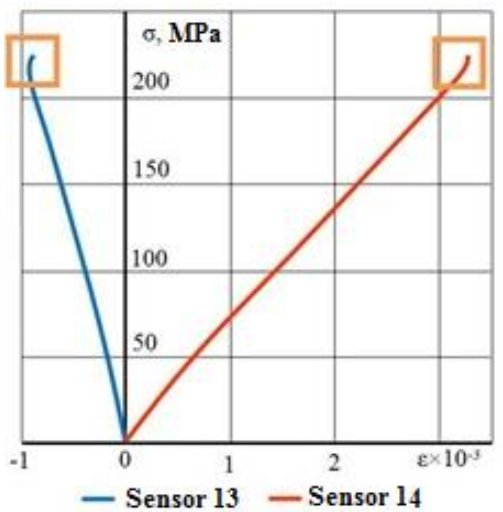

a)
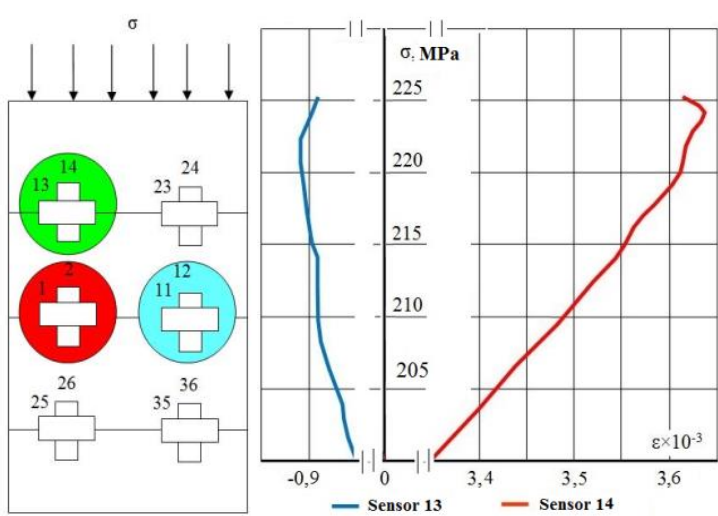

b)

Fig. 6. Reversible character of linear strains in the direction of an axis of the sample (green color area): (a) - full deformations curve, $b$ - near the strength part).

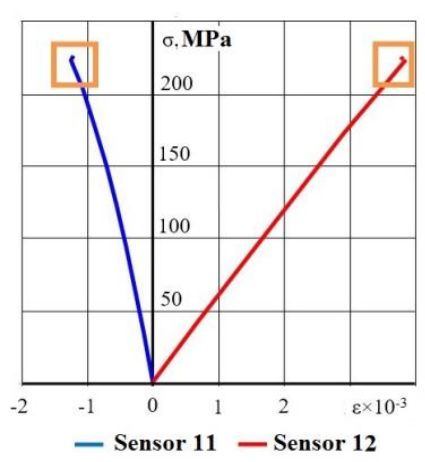

a)
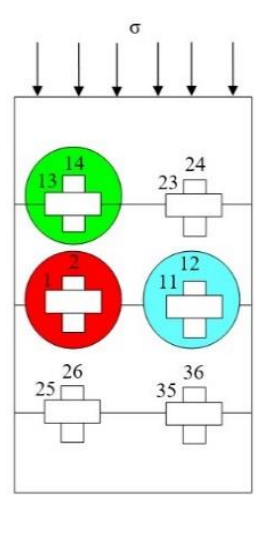

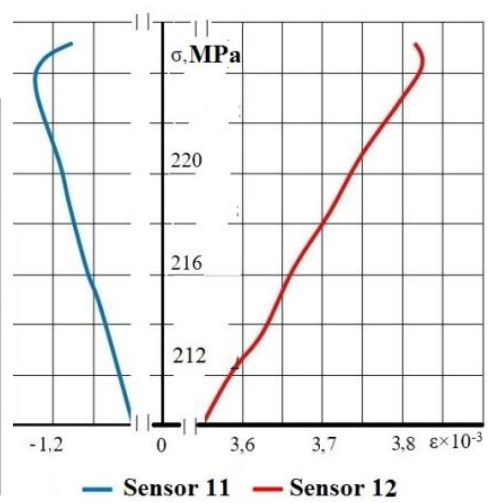

b)

Fig. 7. Reversible character of linear strains in the lateral direction of the sample (blue color area): (a) - full deformations curve, $b$ - near the strength part).

\section{Mathematical model of the phenomenon of reversible deformation of rock samples at uniaxial compression}

The modelling of highly compressed rocks where the deformations conditions of compatibility are not satisfied and the state of the thermodynamic conditions is far from equilibrium by dissipation system generally has well proved at the description of the phenomenon of zonal failure of a massive around the underground openings [32]. Therefore, the mathematical model has been developed and the solution of a problem on the highly compressed sample of rock is developed on the same principals [35].

Deformation anomalies of reversible type occur in the rock sample at achievement by a load $\sigma$ some critical values $\sigma^{*}$. If $\sigma$ it is less than $\sigma^{*}$ stress-strain state of the sample is described within the frame of the elastic theory

$$
\sigma_{i j}=\frac{E}{1+v}\left(\varepsilon_{i j}+\frac{v}{1-2 v} \varepsilon_{k k} \delta_{i j}\right),
$$

where $E$ - elastic modulus, $v-$ Poisson's ratio. 
At $\sigma$ is less than $\sigma^{*}$ the equation of balance for the sample of rock in cylindrical coordinates looks as follows:

$$
\begin{aligned}
& \frac{\partial \sigma_{r r}}{\partial r}+\frac{1}{r} \frac{\partial \sigma_{r \varphi}}{\partial \varphi}+\frac{\partial \sigma_{r z}}{\partial z}+\frac{\sigma_{r r}-\sigma_{\varphi \varphi}}{r}=0, \\
& \frac{\partial \sigma_{r \varphi}}{\partial r}+\frac{1}{r} \frac{\partial \sigma_{\varphi \varphi}}{\partial \varphi}+\frac{\partial \sigma_{\varphi z}}{\partial z}+\frac{2 \sigma_{r \varphi}}{r}=0, \\
& \frac{\partial \sigma_{r z}}{\partial r}+\frac{1}{r} \frac{\partial \sigma_{\varphi z}}{\partial \varphi}+\frac{\partial \sigma_{z z}}{\partial z}+\frac{\sigma_{r z}}{r}=0 .
\end{aligned}
$$

The boundary problem for the allocation of a field of stresses $\sigma_{i j}$ in a cylindrical sample is formulated in a stationary statement (2). The solution is written in the form (2). Let the external force $\boldsymbol{P}=(0,0, P)$ act on the sample ends. Then for balance it is compensated by the force of internal stresses, and the boundary conditions are satisfied at the ends of the sample $\left(S_{ \pm}\right)$and on its lateral surface $(\Gamma)$ :

$$
\int_{S_{ \pm}} \sigma_{i j} n_{j} d S=0, \int_{\Gamma} \sigma_{z j} n_{j} d S=\int_{\Gamma} P d S
$$

The demands (3) are satisfied on the condition that

$$
\begin{gathered}
\left.\sum_{z z}\right|_{z= \pm h}=P,\left.\quad \sum_{z r}\right|_{z= \pm h}=0,\left.\quad \sum_{z \varphi}\right|_{z= \pm h}=0, \\
\left.\sum_{r r}\right|_{r=R}=0,\left.\quad \sum_{r \varphi}\right|_{r=R}=0,\left.\quad \sum_{r z}\right|_{r=R}=0, \\
\left.\int_{0}^{R} r d r \int_{0}^{2 \pi} d \varphi T_{i z}\right|_{z= \pm h}=0,\left.\quad \int_{-h}^{h} d z \int_{0}^{2 \pi} d \varphi T_{i r}\right|_{r=R}=0,
\end{gathered}
$$

where $R$ is the radius of the sample and $2 h$ is its height. The conditions (4) coincide with the classical conditions locally at each point. It is seen from (5) that the components $T_{i j}$ are the self-balanced fields.

To construct $T_{i j}$ the stress function $g$ must be introduced:

$$
T_{i j}=\delta_{i j} \Delta g-\frac{\partial^{2} g}{\partial x^{i} \partial x^{j}} .
$$

It is well known that the classical theory demands $\Delta \Delta g=0$, where $\Delta$ is the Laplace operator. Then $T_{i j}$ satisfies the compatibility conditions. The non-Euclidian model results in the equation

$$
\Delta g=-\gamma g
$$

with a phenomenological parameter $\gamma$. In the cylindrical coordinate system, we have the following expression for the stress components (6): 


$$
\begin{aligned}
& T_{r r}=\frac{1}{r} \frac{\partial g}{\partial r}+\frac{1}{r^{2}} \frac{\partial^{2} g}{\partial \varphi^{2}}+\frac{\partial^{2} g}{\partial z^{2}}, \quad T_{r \varphi}=-\frac{\partial}{\partial r}\left(\frac{1}{r} \frac{\partial g}{\partial \varphi}\right), T_{r z}=-\frac{\partial}{\partial r} \frac{\partial g}{\partial z}, \\
& T_{\varphi \varphi}=\frac{\partial^{2} g}{\partial r^{2}}, T_{z \varphi}=-\frac{\partial}{\partial z}\left(\frac{1}{r} \frac{\partial g}{\partial \varphi}\right), T_{z z}=\frac{\partial^{2} g}{\partial r^{2}}+\frac{1}{r} \frac{\partial g}{\partial r}+\frac{1}{r^{2}} \frac{\partial^{2} g}{\partial \varphi^{2}} .
\end{aligned}
$$

The function $g$ is expressed through the cylindrical function $Z_{n}(k r)$, which is the solution of equation (8). Then the components of a field $T_{i j}$ are given by the following formulae:

$$
\begin{aligned}
& T_{r r}=\left(\frac{1}{r} \frac{d Z_{n}(k r)}{d r}-\frac{n^{2}}{r^{2}} Z_{n}(k r)-q^{2} Z_{n}(k r)\right) \cos \left(n \varphi+\varphi_{0}\right) \cos q z, \\
& T_{r \varphi}=n \frac{d}{d r}\left(\frac{Z_{n}(k r)}{r}\right) \sin \left(n \varphi+\varphi_{0}\right) \cos q z, \\
& T_{r z}=q \frac{d}{d r}\left(Z_{n}(k r)\right) \cos \left(n \varphi+\varphi_{0}\right) \sin q z, \\
& T_{\varphi \varphi}=-\left(\frac{1}{r} \frac{d Z_{n}(k r)}{d r}-\frac{n^{2}}{r^{2}} Z_{n}(k r)+k^{2} Z_{n}(k r)\right) \cos \left(n \varphi+\varphi_{0}\right) \cos q z, \\
& T_{z \varphi}=-q n Z_{n}(k r) \sin \left(n \varphi+\varphi_{0}\right) \sin q z, \\
& T_{z z}=-k^{2} Z_{n}(k r) \cos \left(n \varphi+\varphi_{0}\right) \cos q z .
\end{aligned}
$$

The parameters $q, k$ cannot be arbitrary. The boundary condition at the ends for $T_{z \varphi}, T_{z r}$ demands $\sin q h=0$ which results in a discrete set for the parameter $q: q_{m}=\pi m / h, m \geq 1$. The integrated condition (9) for $T_{z z}$ contains the cylindrical function $Z_{0}(k r)$. This allows us to write the condition in the following form:

$$
\left.\int_{0}^{R} r d r \int_{0}^{2 \pi} d \varphi T_{z z}\right|_{z= \pm h}=-2 \pi(-1)^{m} k^{2} \cos \varphi_{0} \int_{0}^{R} r d r J_{0}(k r)=2 \pi k R J_{1}(k R)(-1)^{m+1} \cos \varphi_{0}=0 .
$$

From here we see that the parameter $k$ is defined by the roots of the Bessel function $J_{1}(z)$.

The common solution of the field components $T_{i j}$ is expressed through a Fourier series. The model numerical calculation was carried out for the experimental research using rock sample characteristics: $v=0.26, E=1.7 * 10^{4} \mathrm{MPa}, \mathrm{h}=5 \mathrm{~cm}, \mathrm{R}=2.5 \mathrm{~cm}$. The calculation results for the deformations at the same experimental conditions are displayed in comparison with the data of this experiment in Table 2. We can see a full qualitative coincidence of the analytical and experimental results, and the maximum quantitative difference of the strain values does not exceed $23 \%$ (Table 3 ).

To develop a new theory of the geomechanics of rock masses at great depths, we need to create conceptual principles that adequately reflect the essence of the processes occurring in these conditions and that involve the physics of new plasticity models. These new representations require the development of principles that describe the characteristics of the rock mass conditions, the model framework, and the methodology for applying this new theory. 
Table 3. Results of the theoretical (non-Euclidian model) and experimental research.

\begin{tabular}{|l|l|l|l|l|}
\hline Degree & $\boldsymbol{\varphi}=\mathbf{0}^{\circ}$ & $\boldsymbol{\varphi}=\mathbf{9 0 ^ { \circ }}$ & $\boldsymbol{\varphi}=180^{\circ}$ & $\boldsymbol{\varphi}=\mathbf{2 7 0}$ \\
\hline \multicolumn{5}{|c|}{ Lateral deformation } \\
\hline$\varepsilon_{\varphi \varphi}^{\mathrm{exp}} \cdot 10^{-6}$ & 69.2 & 9.3 & -11.2 & 55.6 \\
\hline$\varepsilon_{\varphi \varphi}^{\text {theor }} \cdot 10^{-6}$ & 77.5 & 11.0 & -9.5 & 65.5 \\
\hline$\delta_{\varphi, \%} \%$ & 12.0 & 18.3 & 15.2 & 17.8 \\
\hline \multicolumn{5}{|c|}{ Longitudinal deformation } \\
\hline$\varepsilon_{\varphi \varphi}^{\exp } \cdot 10^{-6}$ & -52.9 & 58.9 & -141.7 & 123.0 \\
\hline$\varepsilon_{\varphi \varphi}^{\text {theor }} \cdot 10^{-6}$ & -65.0 & 52.5 & -159.0 & 106.0 \\
\hline$\delta_{\varphi}, \%$ & 22.9 & 10.9 & 12.2 & 13.8 \\
\hline
\end{tabular}

\section{Conclusion}

Thus, satisfactory results of mathematical modelling allow us to determine the mechanism of the phenomenon of reversible deforming of highly compressed rock samples which consists in the conditions of strong non-equal component of compression which cause mesocracking destruction on inhomogeneities of the medium, while strains in the sample have an oscillation of a periodic character that has a consequence development in local fields of action of the maximum normal tangential stresses of the source of concentration of interacting mesodefects, and in the vicinity of the source area - the formation of places where deformations assume a reversible character.

The establishment of the phenomenon of reversible deformation of highly compressed samples of rocks allows us to formulate a system of deformation precursors of failure that is of great value in the forecasting of geodynamic phenomena in a rock massif. The combination of the traditional and new precursors could essentially rise the reliability of the geodynamic phenomena prediction [4]. In addition, the multichannel method of reliable precursors of failure determination must be developed.

\section{Acknowledgements}

The paper was supported by the grants of Ministry of Science and Higher Education of Russia. Unique identifier of the agreement RFMEFI58418X0034.

\section{REFERENCES}

1. X.T. Feng, J.A. Hudson, Rock engineering risk. - CRC Press, 572 (2015)

2. V.V. Makarov, L.S. Ksendzenko, A.M. Golosov, N.A. Opanasiuk, Reversible deformation phenomena of a high stressed rock samples. Rock Engineering and Rock Mechanics: Structures in and on Rock Masses - Alejano, Perucho, Olalla \& Jiménez (Eds) (C) 2014 Taylor \& Francis Group, London, 267-272 (2014)

3. I.S. Tomashevskaya, Ya.N. Khamidullin, Precursors of the destruction of rock samples. Izv. USSR Academy of Sciences. Earth Sciences, 5. 12-20 (1972) (in Russian) 
4. M.A. Guzev, V.N. Odintsev, V.V. Makarov. Principals of geomechanics of highly stressed rock and rock massifs. Tunnelling and Underground Space Technology, 81, 506-511 (2018)

5. M.A. Sadovsky, L.G. Bolhovitinov, V.F. Pisarenko, Deforming of geophysical medium and seismic process, 101 (1987)

6. I.M. Petukhov, I.M. Batugina, Geodynamics of bowels of the earth. 288 (1996)

7. A. Coburn, R. Spence, Earthquake protection. John Wiley AND Sons, 428 (2003)

8. N. Disasters Vulnerability Analysis. Office of the United Nations Disaster Relief Coordinator (UNDRO). - Geneva. 311 (1979)

9. H.H. Einstein Risk and risk analysis in rock engineering. Tunnelling and Underground Space Technology, 11-2, 141-155 (1996)

10. E.V. Leary, Earthquakes: Risk, Monitoring and Research. New York: Nova Science, 526 (2009)

11. P. Folger, Earthquakes: risk, monitoring, notification, and research. Library of Congress Washington DC Congressional Research Service (2008)

12. C.S. Oliveira, A. X. Roca (ed.). Assessing and managing earthquake risk: geoscientific and engineering knowledge for earthquake risk mitigation: developments, tools, techniques. Springer Science AND Business Media, 2 (2009)

13. G. A. Sobolev, A.B. Ponomarev Physics of earthquakes and precursors. 270 (2003)

14. K. Mogi, Earthquake Prediction. Academic Press, Tokyo, 355 (1985)

15. Ragnar Stefansson, Advances in Earthquake Prediction. Research and Risk MITIGATION. Springer-Verlag Berlin Heidelberg 274 (2011)

16. J. Milne, Earthquakes and Other Earth Movements. International scientific series, 56. New York: K. Paul, Trench, 363 (1886)

17. J. Milne, Seismic science in Japan, Trans. seism. Soc. Jpn., 1, 3-33 (1880)

18. W.H. Hobbs, Earthquakes, Appleton. New York, NY (1907)

19. G.K. Gilbert, Earthquake forecasts. Science. 29, 121-138 (1909)

20. H.J. Reid, The California Earthquake of April 18. 1906. Vol. II, The Mechanics of the Earthquake, Rept State Earthquake Investigation Commission, Carnegie Institution of Science. 803-810 (1906)

21. E.A. Hodgson, A proposed research into the possibilities of earthquake prediction. Bull. seism. Soc. Am., 13, 100-104 (1923)

22. H. Landsberg, The problem of earthquake prediction. Science. 82, 37. Washington, Washington, DC (1910)

23. J. Langbein, Earthquake explanations. Nature. 349-6307. 287 (1991)

24. R. J. Geller, Earthquake prediction: a critical review. Geophys. J. Int., 131, 425-450 (1997)

25. C.H. Scholz, L.R. Sykes, Y.P. Aggarw, Earthquake prediction: a physical basis (1971)

26. I.P. Dobrovolsky, Mathematical theory of preparation and the forecast of tectonic earthquake. PHYSMATHLIT, 240 (2009)

27. R.J. Geller, D.D. Jackson, Y.Y. Kagan, F. Mulargia, Earthquakes Cannot Be Predicted. Science. 275-5306 (2009)

28. S.V. Goldin, Makro and mesostructures of the source earthquake areas. The Physical mesomechanics, 8, №1, 3-14 (2005)

29. D.A. Lockner, J.D. Byerlee, V.S. Kuksenko, A. Ponomarev, A. Sidorin, Quasistatic fault growth and shear fracture energy in granite. Nature, 350(7), 39-42 (1991)

30. W.F. Brace et al. Dilatancy in fracture of crystalline rocks. J. Geophys. Research, 16(71), 3930-3953 (1966) 
31. V.V. Makarov, Calculation of lining of city shallow tunnels on action of a surface loading. GIAB, 74-81 (2013) (in Russian)

32. M.A. Guzev, V.V. Makarov, Deforming and failure of the high stressed rocks around openings, Vladivostok: RAS Edit (2007) (in Russian)

33. J.R. Rice,The Mechanics of Earthquake Rupture. In Physics of the Earth's Interior. Italian Physical Society and North-Holland Publ. Co., 555-649 (1980)

34. V.N. Odintsev, Tensile destruction of a brittle rock masses. M: IPKON, Russian Academy of Sciences (1996) (in Russian)

35. M.A. Guzev, V.V. Makarov, A.A. Ushakov, Modeling elastic behavior of compressed rock samples in the pre-failure zone, Journal of Mining Science, 41(6), 497-590 (2005) 